\title{
Experiências profissionais e os sentidos atribuídos à educação física em contexto escolar ${ }^{1}$
}

\author{
Rosângela da Conceição Loyola* \\ Sandra Soares Della Fonte ** \\ Zenólia Christina Campos Figueiredo ***
}

\begin{abstract}
Resumo: O objetivo do estudo foi compreender de que maneira as experiências profissionais singularizam a disciplina Educação Física. Focamos os espaços de interação nos quais ocorria um maior número de experiências produzidas pelos sujeitos na escola. Caracteriza-se como estudo qualitativo, utilizou como principal instrumento a observação participante em espaços-tempos de interação, além dos diálogos e análise de documentos. Os sujeitos colaboradores foram: diretora, pedagogas, professoras regentes e duas professoras de Educação Física. Foram identificadas algumas significações, quais sejam: Educação Física como curinga; disciplina menor; centro das festividades; e lugar de tensão entre profissionalização e desprofissionalização.

Palavras-chave: Educação Física. Prática profissional. Docentes.
\end{abstract}

\section{INTRODUÇÃO}

Penetrar nas redes de relações existentes em uma escola, buscando os pontos de encontros, de rupturas e de conflitos supõe ser fundamental para compreender os significados constituídos pelos profissionais da educação em suas experiências, em especial, aquelas relacionadas com a Educação Física no contexto da escola.

\footnotetext{
${ }^{1}$ Este artigo corresponde a uma parte da dissertação de mestrado intitulada "Experiências Profissionais na Escola e os Sentidos da Educação Física" - Programa de Pós-Graduação em Educação Física, Universidade Federal do Espírito Santo, 2009.

* Professora Adjunto do Centro de Educação Física e Desportos. Professora Pesquisadora do Laboratório de Estudos em Educação Física (LESEF). Doutora em Educação. Vitória, ES, Brasil. E-mail: sandra@cefd.ufes.br

** Professora Adjunto do Centro de Educação Física e Desportos. Professora Pesquisadora do Laboratório de Estudos em Educação Física (LESEF). Doutora em Educação. Vitória, ES Brasil. E-mail: sandra@cefd.ufes.br

*** Professora Adjunto do Centro de Educação Física e Desportos. Coordenadora do Práxis Centro de Pesquisa de Formação Inicial e Continuada em Educação Física. Doutora em Educação. Vitória, ES, Brasil. E-mail: zenolia@npd.ufes.br
} 


\section{Artigor Orifimais Rosângela da Conceição Loyola et al.}

Buscamos, nos espaços de interações, as posições e ações dos sujeitos que produzem e reproduzem significados a partir de experiências construídas ao se relacionarem entre si na prática docente. Esse recorte tomou como referência o estudo de Heringer (2008), pautado nas contribuições de Correa (1999), que nos remete às ocultações, no que se refere a interferência que a organização do trabalho docente exerce sobre as experiências de formação continuada dos professores; a idéia de forçar uma relação de causalidade linear entre a eficácia da ação educativa e a eficácia do desempenho profissional, desvalorizando a importância da qualidade da organização e da interação entre os sujeitos; a desconsideração da legitimidade dos saberes profissionais construídos nas relações entre os professores; a determinação prévia das necessidades de formação do indivíduo; além de uma noção de qualidade sem espaço para discussões coletivas.

Nesse sentido, Heringer (2008, p. 28), nos diz que “[...] as diferentes reações se devem à individualidade de cada sujeito e à forma como se organiza cada espaço". Uma das contribuições do seu estudo foi indicar que, dependendo do profissional de Educação Física e de sua postura diante da vida escolar, esse componente curricular ganha uma determinada feição.

Tanto essa idéia de investigar o sujeito e suas relações no contexto de atuação, como a de investigar ou tomar a escola como locus privilegiado de investigação para tantas questões, e também para espaços de acontecimentos que a definem como lugar comum, (SMOLKA, 2006) fazem todo o sentido nesse trabalho.

Os lugares são importantes instâncias de produção de ocultações e, portanto, de grande relevância para a produção de "ilusões partilhadas" (CORRÊA, 1999). Desse modo, buscamos compreender os sentidos das experiências profissionais na escola como instituição social, considerando que o contexto escolar sofre influência permanente das demandas advindas da contemporaneidade, da mesma forma que os sujeitos que a constituem. Tornar visível o que está invisível a partir das experiências profissionais é buscar formas de conviver, sentir, pensar e compartilhar a vida. Isso não se faz sem tocar os processos sociais, sobretudo os mais sutis.

Movimento, Porto Alegre, v. 17, n. 01, p.177-193, janeiro/março de 2010. 
Sendo assim, aproximamo-nos da escola, para entender como os profissionais da Educação operam no dia a dia os mecanismos de dominação e resistências, de apropriação e rejeição, e também para apontar as contradições, a fim de compreender como se configuram os processos relacionados com as escolhas que os mesmos realizam como profissionais da Educação, em especial da Educação Física, no que se refere aos dilemas contemporâneos.

Para a compreensão dessa questão central e de outras tantas que circundam o objeto, utilizamos Dubet (1994), Lahire (2002) e Dubar $(2005,2006)$ como interlocutores. Nossas questões iniciais são: quais os sentidos de Educação Física engendrados pelas relações profissionais vividas no contexto escolar? Que traços singularizam a Educação Física perante alguns profissionais da escola?

Organizamos o texto a partir de uma breve descrição das escolhas metodológicas e, posteriormente, tratamos das principais significações analisadas na escola investigada: Educação Física como curinga; disciplina menor; centro das festividades; e lugar de tensão entre profissionalização e desprofissionalização.

\section{As ESCOLHAS METODOLÓGICAS}

As escolhas metodológicas deste estudo foram referenciadas pela Sociologia da Experiência, cujo foco central é a investigação da ação humana dotada de sentido. O objeto foi se constituindo com a preocupação de compreender de que maneira as experiências profissionais atribuem singularidade à disciplina Educação Física nos diferentes espaços de interação entre os profissionais na tentativa de perceber as lógicas que levam essas experiências a definir o "lugar" da Educação Física nesse referido contexto.

Para a escolha da escola, definimos um primeiro critério: espaços que favorecem as interações. Pensamos que ao definir um espaço no qual as interações são favorecidas, as possibilidades de apreender aspectos da construção desse lugar que a Educação Física ocupa, são mais profícuas ao estudo. Desse modo, buscamos auxílio em Frago (1995, p. 17), que diz que "[...] a arquitetura da

Movimento, Porto Alegre, v. 17, n. 01, p. 177-193, janeiro/março de 2011. 
escola não se configura somente em um lugar; ela se apresenta como um construto cultural que reflete, para além de sua materialidade, determinados discursos".

Dentre as 51 escolas do sistema municipal de ensino em 2007, 11 atenderam ao critério de prédio horizontal, o que segundo Frago (1995), facilita os processos de interação. Essas escolas estão localizadas em regiões com diferenças significativas em termos socioeconômicos (população, habitação, saneamento básico, escolaridade, renda familiar). ${ }^{2}$

Nosso propósito era definir uma escola dentre as onze identificadas, segundo o critério de prédios horizontais, por isso recorremos aos assessores ${ }^{3}$ a fim de delimitar esse universo. Esse procedimento nos permitiu sistematizar novos percursos metodológicos que possibilitou definir a escola lócus da pesquisa a partir de um segundo critério: escolas que, por meio de múltiplas ações, fomentam interações entre os sujeitos.

Definida a escola, passamos à escolha dos instrumentos de pesquisa. Utilizamos a observação participante, cujo objetivo foi focar o olhar em experiências vivenciadas no contexto escolar que tivessem possíveis relações com a disciplina Educação Física, a fim de compreender de que maneira essas experiências atribuem singularidade a essa disciplina naquela escola. Estivemos presentes: a) nos planejamentos integrados, b) nas reuniões de professores, c) nas reuniões de pais e professores, d) nos recreios de professores, e) nos conselhos de classe, f) nas festividades. Também estabelecemos diálogos de caráter informal com os sujeitos e analisamos os documentos oficiais da escola.

Para definir a documentação a ser analisada, recorremos às contribuições de Sarmento (2003, p. 164), quando nos diz que:

Os documentos podem ser textos projetivos da ação - planos de aula, projetos da escola,

\footnotetext{
2 Instituto Brasileiro de Geografia e estatística (IBGE, 1991-2000). Secretaria Municipal de Educação de Vitória-ES (SEMA, 2007).

${ }^{3}$ Professores de diferentes áreas que atuam na Secretaria Municipal de Educação, com a função de estabelecer pontes entre a Secretaria de Educação e as escolas.

Dovimento, Porto Alegre, v. 17, n. 01, p.177-193, janeiro/março de 2010.
} 
planificações, regulamentos etc. Produtos da ação - relatórios, atas, memorandas e outros documentos que são escritos no decurso das atividades e adquirem aí uma forma definitiva; e documentos performativos, isto é, textos que constituem em si mesmos a ação porque têm o fim em si-jornais escolares, notícias de jornal de parede, redações e diários.

Com base nessas "pistas" e possibilidades de análise trazidas por Sarmento (2003), buscamos conhecer como documentos projetivos de ação, os projetos da escola; como documentos produtos da ação, as atas de reuniões e memorandos; e como documentos performativos, os murais informativos, bilhetes enviados para a casa dos alunos, e as fotos das festividades da escola.

Tendo definido o lugar e os procedimentos de investigação, pensamos nos sujeitos que poderiam tornar colaboradores da pesquisa. Optamos por privilegiar dentre os profissionais que atuam na escola, as pedagogas, a diretora, as professoras regentes e de Educação Física e as coordenadoras, todas do turno vespertino, por serem as que estão presentes nos vários espaços e tempos dos quais participamos.

\section{EdUCAÇÃo FíSICA: O LUGAR DE MORTO E OS ENTRE LUGARES}

Pautamos as análises e interpretações nas contribuições de Dubet (1994), ao focar a experiência como uma articulação de lógicas próprias advindas dos sistemas comunidade, mercado e sistema cultural, de Lahire (2002), no que se refere à pluralidade dos contextos, e de Dubar (2005-2006), com relação às crises e mutações decorrentes dessas relações entre contexto e experiência vividas. Desse diálogo teoria e empiria foi possível entender e visualizar como as ações são centrais e convergentes, considerando que não há experiência sem relação consigo, com os outros e com o mundo, assim como não há socialização sem relação humana.

Quais os sentidos de Educação Física engendrados pelas relações profissionais vividas no contexto escolar? Que traços singularizam a Educação Física perante alguns profissionais da escola?

Movimento, Porto Alegre, v. 17, n. 01, p. 177-193, janeiro/março de 2011. 


\section{Artigor Orifimais Rosângela da Conceição Loyola et al.}

Identificamos, sobretudo, nas observações das ações cotidianas, possibilidades interpretativas bastante interessantes para pensar sobre essas questões, nesse artigo priorizamos quatro significações: Educação Física como curinga; disciplina menor; centro das festividades; e lugar de tensão entre profissionalização e desprofissionalização. Para conseguir contemplá-las, apresentamos menos as situações observadas e mais as sínteses construídas em torno delas. Sugerimos ao leitor, no entanto, que caso tenha interesse em conhecer as descrições das observações na íntegra, que faça a leitura da dissertação de mestrado que deu origem ao presente artigo.

\subsection{EDUCAÇÃO FÍSICA COMO UMA DISCIPLINA CURINGA} PARA A REALIZAÇÃO DOS PLANEJAMENTOS INTEGRADOS

são chamados de planejamentos integrados os encontros realizados duas vezes por semana na Escola "Tempo de Agir" e que envolvem grupos de professores regentes, professor de Informática e de Educação Especial, juntamente com uma pedagoga. Para cada grupo, existe um horário específico, de tal forma que cada série é atendida em momentos diferentes. Cada pedagoga fica responsável por dois grupos. O objetivo primordial desse planejamento é discutir as necessidades dos alunos para buscarem alternativas para as situações apresentadas, a partir da mediação e das orientações das pedagogas. No total, observamos quinze encontros.

A organização e dinâmica dos planejamentos indicam que todas as professoras têm seis momentos de 50 minutos para a sua realização que acontecem da seguinte forma: a) três momentos para formulação de atividades e elaboração de materiais didáticos; b) um momento para o trabalho individualizado com as crianças com deficiência e ou dificuldade de aprendizagem; c) um momento para agendar com os pais uma conversa sobre seus filhos; d) um momento integrado entre professoras regentes das três primeiras séries, o professor do laboratório de informática e a professora especialista da educação inclusiva na escola.

No entanto, não se percebe a presença das professoras de Arte, de Língua Inglesa e de Educação Física nesses encontros. Esse fato ocorre, segundo as pedagogas, porque essas disciplinas garantem

Movimento, Porto Alegre, v. 17, n. 01, p.177-193, janeiro/março de 2010. 
a participação das professoras, enquanto os alunos estão em aula, nessas disciplinas. Em conversa informal no recreio, a pedagoga explica a ausência da Educação Física: "pelo fato de não poder liberar os alunos, nem sempre é possível organizar a escola para envolver todos".

Essa organização escolar observada possui uma intencionalidade e, portanto, não é neutra à medida que se configura em "Lugares comuns de caráter complexo, heterogêneo. Sentidos entretecidos às condições concretas de vida que articulam as dimensões individuais, sociais, históricas, ideológicas das experiências singulares e coletivamente vividas" (PIMENTA, 1999, p. 98).

A essa situação complexa podemos associar ao que Smolka (2006) denomina de (con)tradição da experiência ou (in)tensos sentidos e heterogeneidade do lugar comum. Lembra-nos, também, a explicação de Nóvoa (1992), ao se referir à metáfora de bridge $e^{4}$, em que um dos parceiros de um jogo ocupa o "lugar de morto", sendo obrigado a expor a suas cartas em cima da mesa. Nenhuma jogada pode ser feita sem atender às suas cartas, mas o jogador, dono das cartas não pode interferir no desenrolar do jogo. Essa metáfora é usada pelo autor para analisar três triangulações: 1) o triângulo pedagógico (professores, saber e alunos); 2) o triângulo político (professores, Estado e pais/comunidade); e 3) o triângulo do conhecimento (saber da Pedagogia, saber da experiência e saber das disciplinas). $\mathrm{O}$ "lugar de morto" nessas triangulações diz respeito, segundo Nóvoa, aos processos de exclusão do professor.

Para Dubar (2005), essa socialização é entendida como um processo dinâmico, permitindo a construção, desconstrução e reconstrução de identidades. Ele entende a identidade como o resultado de uma socialização e defende que o conceito de identidade depende da trajetória de vida do indivíduo e da configuração social de cada momento de sua vida. Por sua vez, Dubet (1994) nos alerta que esses processos de socialização envolvem conflitos.

${ }^{4}$ Metáfora encontrada no prefácio da $2^{\mathrm{a}}$ edição do livro organizado por Nóvoa.

Movimento, Porto Alegre, v. 17, n. 01, p. 177-193, janeiro/março de 2011. 


\section{Artigos Orifinais Rosângela da Conceição Loyola et al.}

$\mathrm{Na}$ escola investigada o "lugar do morto" é ocupado pela Educação Física, tomando emprestada a metáfora de Nóvoa (1992, p. 7) "[...] está presente, tem de ser levado em consideração, mas a sua voz não é essencial para fixar o desfecho dos acontecimentos". Entretanto, como identificamos nas observações, essa posição de "morto" não ocorre sem resistências. Por isso, a importância de compreender os processos culturais de subjetivação, por se edificar e se desenvolver nas e por meio das relações com o outro.

Outro elemento a se destacar é que essa organização dos supostos planejamentos integrados compõe a experiência social docente nessa escola e, nesse sentido, vincula-se à construção, desconstrução e reconstrução da identidade profissional.

Refletir sobre essa questão nos leva a compreender que:

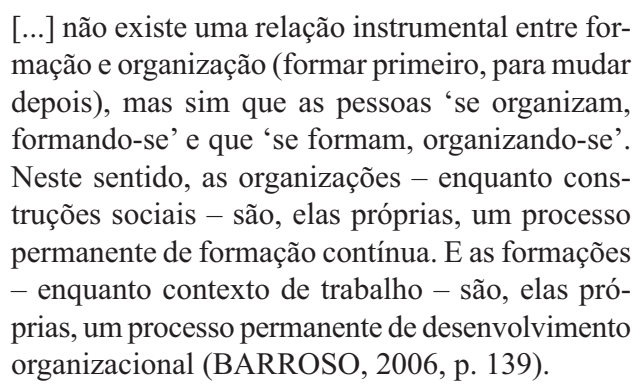

Para esse autor, os processos de formação e organização estão imbricados e são dependentes um do outro. Entretanto, na escola em questão, o processo de construção identitária do que é ser docente não é homogêneo. Por mais que existam elementos em comum vinculados ao ensino, as professoras regentes e as de Educação Física, vivenciam experiências diferenciadas na sua socialização profissional e, nesse aspecto, a identidade docente também se mostra heterogênea.

\subsection{EDUCAÇ̃̃O FISICA COMO DISCIPLINA MENOR}

em conversas com os profissionais da Escola, por mais diversos que tenham sido os argumentos utilizados, foi unanimidade a afirmação de que a Educação Física é importante para o currículo

Movimento, Porto Alegre, v. 17, n. 01, p.177-193, janeiro/março de 2010. 
escolar. Entretanto, na escola investigada bem como em alguns estudos realizados na área, identifica-se que afirmações como essa se apresentam no mínimo contraditórias se considerados os dados advindos do cotidiano escolar. Figueiredo et al. (2008) apontam algumas ações que se materializam na Educação Física quando: a) da recusa de alunos que não participam das aulas por não considerarem importantes; b) da prioridade de certos saberes em detrimento de outros; c) da valorização do saber utilitário; d) do estereótipo esportivo atribuído ao professor. Essas constatações acrescidas às informações coletadas por nós indicam que apesar de os sujeitos afirmarem da importância inquestionável da Educação Física, na prática ela se torna secundária na relação de espaço e tempo com as outras disciplinas e vem se caracterizando no contexto escolar como disciplina menor.

Em nosso trabalho de campo essa característica aparece traduzida nos seguintes aspectos: a Educação Física como disciplina não séria e como disciplina de suporte do conteúdo desenvolvido pela professora regente.

Para ilustrar a primeira situação, recorremos aos bilhetes encaminhados aos pais pelas pedagogas e coordenadoras. Esses bilhetes tinham como finalidade informar e envolver os pais nas questões pedagógicas da escola, quando enviados pelas pedagogas. Já os bilhetes encaminhados pelas coordenadoras comunicavam aos pais ou responsáveis questões referentes à disciplina dos alunos, às saídas para as aulas de campo, etc.

Em nenhum dos bilhetes enviados aos pais e analisados por nós, percebemos quaisquer referência à Educação Física, uma vez que, nesses bilhetes os pais ou responsáveis eram chamados para conversas relacionadas com o ensino, no que tange às dificuldades de aprendizagens e possibilidades de intervenção. Desse modo, indagamos: que disciplina é essa que não suscita nenhuma questão quanto à aprendizagem do aluno e possibilidades de intervenção? Por que os eventos do processo de ensino-aprendizagem que ocorrem no tempo e espaço da Educação Física não são levados em consideração?

Movimento, Porto Alegre, v. 17, n. 01, p. 177-193, janeiro/março de 2011. 


\section{Artigor Orifimais Rosângela da Conceição Loyola et al.}

O único momento no qual percebemos o envio de um bilhete foi quando a professora Júlia, em reunião, solicitou às pedagogas que informasse aos pais sobre a necessidade de arrumar e acompanhar os filhos no dia da festa Junina ${ }^{5}$. O retorno desses bilhetes assinados pelos pais ou responsáveis se constituiu em critério para a definição dos alunos que iam ensaiar as danças para apresentação no dia da festa.

Encontramos outro exemplo sobre o sentido de não seriedade da Educação Física nos recreios das professoras. Em geral, esse intervalo apresenta-se como uma oportunidade para conhecer um pouco mais de suas histórias, limites, possibilidades, valores, crenças, etc. Esse momento, a princípio, é considerando sagrado pelos professores, por ser um tempo de se libertar, temporariamente, de todas as angústias vivenciadas na sala de aula.

Nesse espaço, as professoras, inclusive as de Educação Física, reclamavam sobre a ausência de participação delas nas decisões da escola, referindo-se a datas marcadas e a encaminhamentos comunicados pelas pedagogas após reunião com a diretora.

Em um desses recreios, Júlia perguntou à professora Flora porque um dos alunos de sua turma não foi para a aula de Educação Física, já que ele estava na sala de aula. Flora respondeu que ele não fez a tarefa e estava agitado, por isso considerou que ele não poderia ir para a aula de Júlia.

Essas situações trazem vários pontos de discussão. Aqui novamente identificamos a posição de Júlia ao questionar questões afetas ao exercício docente. Também podemos observar que há um interesse dos alunos pela Educação Física. Em conversa informal, a maioria dos alunos indicou que a Educação Física era a disciplina de sua preferência. Diante disso, o professor regente se aproveita dessa situação e transforma essa disciplina em um mecanismo para punir ou não o aluno de acordo com o comportamento apresentado.

${ }^{5}$ Abordaremos mais à frente o papel da Educação Física na festa junina.

Mevimento, Porto Alegre, v. 17, n. 01, p.177-193, janeiro/março de 2010. 
Contudo, para isso ocorrer, existe um imaginário no qual a Educação Física ocupa um lugar menor.

\subsection{A EdUCAÇÃO FÍSICA COMO CENTRO DE FESTAS ESCOLARES}

consolidando a ideia de que a Educação Física da escola é determinada, dentre outros, pela ação docente, o assunto festas escolares parece ter assegurado o que se desejava e se esperava da disciplina no trabalho da escola. Apesar das incoerências, percebe-se um esforço dos diferentes seguimentos profissionais - a diretora, as pedagogas, as professoras regentes e inclusive das professoras de Educação Física, para assegurar o evento festa junina, por meio da organização do trabalho da disciplina.

Nesse esforço nota-se certa ambiguidade nos modos de atuar dos profissionais, em especial de uma das professoras de Educação Física. Tivemos a impressão que mesmo reconhecendo o estigma de relacionar a Educação Física com festas, a professora assume a responsabilidade pelas festividades da escola, como festa junina e outras, na tentativa de ver reconhecido o lugar da disciplina e da sua intervenção na vida escolar.

Podemos identificar que essa ambigüidade pode vincular-se à compreensão de Goodson (2008 p. 21) quando considera que as formas de conhecimento que produzimos e utilizamos estão estreitamente ligadas às percepções que temos de nós próprios e às projeções que fazemos de nós mesmos. Do mesmo modo, as formas de conhecimento que os profissionais possuem estão substancialmente implicadas no tipo de pessoas que são e que acreditam ser. Contudo, essas formas de conhecimento podem ser reestruturadas. Como resultado disso, acirra-se a tensão entre o tipo de pessoa que os docentes são e aquilo que os outros entendem que eles sejam (DUBAR, 2006).

No decorrer de todo o tempo em que estivemos presentes na escola, somente no episódio que envolvia a festa junina observamos uma coesão entre as diversas disciplinas. Com a ajuda da pedagoga foram organizados os dias e os horários em que as regentes ajudariam as professoras de Educação Física nos ensaios das danças para a

Wovimento, Porto Alegre, v. 17, n. 01, p. 177-193, janeiro/março de 2011. 
festa. Percebemos aí um empenho das pedagogas e da diretora para que o planejamento integrado acontecesse em função da festa junina.

No dia da festa, a diretora da escola anunciou à comunidade que todo o valor arrecadado seria utilizado para a comemoração do dia das crianças e dia dos Professores. Neste caso, a festa representa uma oportunidade de angariar algum fundo para além daquele determinado pela política municipal. Nesse momento, percebemos que a Educação Física ganhou centralidade e, a partir dela, buscou-se a integração profissional e a organicidade da instituição.

3.4 EdUCAÇÃo FísICA ENTRE LUGARES: TENSA RELAÇÃO ENTRE PROFISSIONALIZAÇÃO E DESPROFISSIONALIZAÇÃO

Realçamos que na Escola Tempo de Agir ${ }^{6}$, a Educação Física vive um paradoxo mais forte que outras disciplinas, a que se revela na tensão entre profissionalização e desprofissionalização que se acirra, se potencializa ou relativiza pela própria intervenção do profissional, ou seja, a prática exercida pelas professoras pode contribuir para amenizar ou corroborar os problemas identificados. Ademais, aqui se fortalece estudos no âmbito da área que já vem evidenciando que os modos de significar a Educação Física têm relação estreita com o sujeito que assume a função de docente nessa disciplina.

Nesse caso, ressaltamos dois pontos a serem discutidos. $\mathrm{O}$ primeiro retoma o modo como o planejamento conjunto com a pedagoga aparece na experiência social das professoras de Educação Física, agora por revelar tensão na profissionalização. O segundo relaciona-se com as diferenças de intervenção profissional entre as professoras de Educação Física.

Existe uma ambiguidade no sentido conferido ao planejamento da Educação Física. Ora ele é completamente negligenciado, ora é valorizado e sua realização exigida. Essa negligência ou valorização não é exercida por sujeitos fixos. Em alguns casos, as pedagogas

\footnotetext{
${ }^{6}$ Nome fictício atribuído a escola lócus da pesquisa. Os nomes das professoras que aparecem nesse artigo também são fictícios, a fim de preservar a identidade das colaboradoras.

Mevimento, Porto Alegre, v. 17, n. 01, p.177-193, janeiro/março de 2010.
} 
demandam a participação das professoras que, por sua vez, recuam. Em outras situações, as professoras exigem a efetivação do planejamento e as pedagogas não atendem a essa demanda. Portanto, existe, nessa forma de socialização, uma corresponsabilidade no que tange aos problemas acerca do cotidiano do planejamento conjunto.

$\mathrm{O}$ segundo ponto de destaque relaciona-se com as posturas profissionais diferenciadas entre as professoras de Educação Física. As duas professoras possuem contratos de trabalho diferenciados na instituição, o que dá margens a diferentes atuações. Para além da diferença de contrato de trabalho, percebemos diferenças entre as professoras de Educação Física em seu modo de agir nos vários espaços-tempos interativos. Júlia sempre apresentava mais iniciativa. Nas conversas informais, sabia-se que Lurdes ansiava por sua aposentadoria que demoraria menos de um ano para sair.

Em vários momentos, observamos essa característica peculiar da Júlia. Em uma reunião, as professoras reclamaram sobre a falta de envolvimento em algumas decisões que dizem respeito à docência. Então, a pedagoga Melani ressaltou que, pelo fato de não poder liberar os alunos, nem sempre é possível organizar a escola para envolver todos os profissionais. Sentindo-se provocada pela fala da pedagoga, Júlia diz: "Penso que a falta de inserção do professor ou da área depende de como essa área é vista na escola".

Chamou-nos a atenção a ausência das professoras de Educação Física no planejamento da reunião de pais. Essa ausência gerou malestar, porque, no dia em que aconteceu a reunião com os pais dos alunos das $1^{\mathrm{a}}$ e $2^{\mathrm{a}}$ séries, Júlia estava na escola e sua aula de quinta-feira era prevista para planejamento. Não havia nenhum impedimento para sua participação. No entanto, ela não foi comunicada, mas ficou atenta à movimentação da reunião. Minutos antes do horário previsto para o encerramento desse encontro, Júlia se aproximou da sala e, quando a pedagoga Maurícia ia dar por encerrada a reunião, Júlia disse: "A reunião ainda não acabou". Dirigiu-se aos pais, apresentou-se, falou dos jogos e brincadeiras, conteúdos selecionados para aula de Educação Física para as turmas em que atua.

Wovimento, Porto Alegre, v. 17, n. 01, p. 177-193, janeiro/março de 2011. 
Essa posição de Júlia foi um marco. Nas demais reuniões de pais, apesar de acontecerem no horário de aula das professoras de Arte, Educação Física e Língua Inglesa, observamos que houve, por parte das pedagogas, a preocupação de reservar um tempo para a fala desses profissionais, buscando uma organização diferente a partir da contribuição dos estagiários da escola. A postura de Júlia contribuiu para mudança em um dos momentos da organização escolar. Ela inverteu uma situação desfavorável não só para a disciplina Educação Física, mas também para Arte e Língua Inglesa.

A postura de Júlia indica que o engajamento nas ideias e nas práticas institucionais pode auxiliar e permitir, ao mesmo tempo, o professor agir como sujeito individual, participar da construção coletiva do conhecimento e formar a sua consciência coletiva.

É por essa razão que a identidade se faz por processos de atribuição e de incorporação. Assim, a identidade social não é mera herança de uma geração a outra; é também engendrada por meio das estratégias identitárias desenvolvidas nas instituições pelas quais os indivíduos têm a possibilidade de transformar.

\section{CONSIDERAÇÕES FINAIS}

Entendemos, conforme Dubet (1994), que as experiências são práticas sociais produzidas mediante a relação entre lógicas de ação vivenciadas. Nesse sentido, investigamos a escola Tempo de Agir, focando as experiências dos professores, de Educação Física, diretora, pedagogas e demais professoras regentes em espaços de interação, visando captar as experiências desses sujeitos e os modos de significar a educação física no contexto dessa escola. A partir das análises desse processo podemos considerar as significações de que a educação física aparece como coringa (o lugar do morto), disciplina menor, centro das festividades, lugar de acirrada tensão entre profissionalização e desprofissionalização (os entre lugares), o que em nosso modo de ver geram desafios para a docência, em especial para a Educação Física.

Movimento, Porto Alegre, v. 17, n. 01, p.177-193, janeiro/março de 2010. 
Nesse contexto a disciplina sofre influências internas pelas condições de trabalho e pelos modos como os demais profissionais a vêem, inclusive as professoras de Educação Física, e externa pelas políticas e seus determinantes sociopolíticos. Nesse jogo conflituoso a Educação Física é significada de forma a ser valorizada quando de interesse maior da escola, ora desvalorizada. Essa última tendeu a ser constante, enquanto a valorização perpassou alguns momentos pontuais e por vezes, frágeis.

Com base no exposto, é possível afirmar que a pesquisa realçou alguns elementos das experiências profissionais existentes, contribuindo assim, para apreender disputas em torno de um status profissional, favorecendo outros estudos que tenham interesse pela análise das diferentes formas de lutas empreendidas acerca da identidade do profissional de Educação Física.

Movimento, Porto Alegre, v. 17, n. 01, p. 177-193, janeiro/março de 2011. 
192 Artigos Origimais Rosângela da Conceição Loyola et al.

Professional experience and meanings assigned to physical education in the school context

Abstract: The objective of study was to understand how professional experiences single the discipline Physical Education. We focus on the spaces of interaction occurred in which a larger number of experience produced by the subjects at school. It is characterized as a qualitative study was used as the main instrument of participant observation in space time interaction, in addition to dialogues and document analysis. The subjects were employees: director, educators, teachers, conductors and two teachers of Physical Education. Identified some meanings, which are: Physical Education as a wildcard, less discipline, the center of the festivities, and place of tension between professionalism and disprofissionalization.

Keywords: Physical Education. Professional practice. Faculty.

Experiencia profesional y los sentidos asignados
a la educación física en el contexto de la escuela
Resumen: El objetivo del estudio fue comprender de
qué manera las experiencias profesionales singularizan
la asignatura Educación Física en la escuela. Enfoca-
mos los espacios de interacción en los cuales ocurría
un número más elevado de experiencias producidas
por los sujetos en la escuela. Caracterizase como es-
tudio cualitativo que utilizó como principal instrumento
la observación participante, además de los diálogos,
observación de espacios-tiempos de interacción y
análisis de documentos. Los sujetos colaboradores
fueron: directora, pedagogas, maestras principales
del aula y de Educación Física. Identificados algunos
significados, que son: Educación Física como comodín;
asignatura menor; centro de las festividades escolares;
y lugar de tensión entre profesionalización y despro-
fesionalización.
Palabras-clave: Educación Física. Práctica profe-
sional. Docentes.

\section{REFERÊNCIAS}

BARROSO João. A formação dos professores e a mudança organizacional das escolas. In: FERREIRA, Naura Syria Carapeto (Org.). Formação continuada e gestão da educação. São Paulo: Cortez, 2006. p. 117-143.

Movimento, Porto Alegre, v. 17, n. 01, p.177-193, janeiro/março de 2010. 
BRACHT, Valter. Educação física e aprendizagem social. Porto Alegre: Magister, 1992.

CORREA, José. Os lugares comuns na formação de professores. Lisboa: Ed. Porto, 1999.

DUBAR, Claude. A socialização: Construção das identidades sociais e profisssionais. São Paulo: Martins Fontes, 2005.

A crise das identidades: a interpretação de uma mutação. Porto: Edições Afrontamento, 2006.

DUBET, François. Sociologia da experiência. Lisboa: Instituto Piaget, 1994.

FIGUEIREDO, Zenólia Christina Campos et al. Educação física, ser professor e profissão docente em questão, Pensar a prática, Goiânia, v. 11, n. 2, p. 209-218, maio/ago. 2008.

FRAGO, Antônio Vinão. Do espaço escolar e da escola como lugar: propostas e questões. In: FRAGO, Antônio Vinão; ESCOLANO, Agustin. Currículo espaço e subjetividade: a arquitetura como programa. 2. Ed. Rio de janeiro: DP\&A, 2001. p. 60-139.

GOODSON, Ivor. Conhecimento e vida profissional: estudo sobre educação e mudança. Lisboa: Porto Editora, 2008.

HERINGER, D. Práticas de formação continuada de uma professora de educação física: ocultações, contradições e possibilidades. 2008. Dissertação (Mestrado em Educação Física) - Universidade Federal do Espírito Santo, Vitória, 2008.

LAHIRE, Bernard. O homem plural: os determinantes da ação. Petrópolis: Vozes 2002.

MORGADO, José Carlos. Currículo e profissionalidade docente. Lisboa: Porto Editora, 2005.

NÓVOA, Antônio. Profissão professor. Lisboa: Editora Porto, 1992.

PIMENTA, Selma Garrido. Formação de professores: identidade e saberes da docência. In: PIMENTA, Selma Garrido (Org.). Saberes pedagógicos e atividade docente. São Paulo: Cortez, 1999. p. 15-34.

SARMENTO, Manuel Jacinto. O estúdio de caso etnográfico em educação. In: ZAGO, Nadir; CARVALHO, Marília Pinto de; VILELA, Rita Amélia Teixeira. (Org.). Itinerários de pesquisa: perspectivas qualitativas em sociologia da educação. Rio de Janeiro; DP\&A, 2003. p. 136-179.

SMOLKA, Ana Luiza Bustamante. Experiências e discurso como lugares da memória: a escola e a produção de lugares comuns. Pro-posições, Campinas, v. 17, n. 2, p. 99-118, maio/ago. 2006.

Recebido em: 22.07.2010

Aprovado em: 24.03.2011

Wovimento, Porto Alegre, v. 17, n. 01, p. 177-193, janeiro/março de 2011. 